\title{
Exploratory serial narratives
}

Récits sériels exploratoires

\section{Marta Boni and Camille Martinez}

Translator. Société Coup de Puce Expansion

\section{(2) OpenEdition}

\section{Journals}

Electronic version

URL: https://journals.openedition.org/pratiques/10354

DOI: $10.4000 /$ pratiques. 10354

ISSN: 2425-2042

Publisher

Centre de recherche sur les médiations (CREM)

Electronic reference

Marta Boni and Camille Martinez, "Exploratory serial narratives", Pratiques [Online], 181-182 | 2019,

Online since 15 January 2021, connection on 05 September 2021. URL: http://

journals.openedition.org/pratiques/10354 ; DOI: https://doi.org/10.4000/pratiques. 10354

This text was automatically generated on 5 September 2021.

(c) Tous droits réservés 


\title{
Exploratory serial narratives
}

\author{
Récits sériels exploratoires
}

\author{
Marta Boni and Camille Martinez \\ Translation : Société Coup de Puce Expansion
}

1 Studying storytelling in the contemporary, digital, polymediated age means confronting the increasing number of serialised narratives intended for all types of screens, particularly television, be it traditional linear television or new television services, such as provided by Netflix or Amazon. Such serial shows, which viewers binge-watch over days, months and years have led many scholars to frame narratives primarily in terms of their time dimension. Analysts of serial television shows agree that they are richly detailed, fragmented, audiovisual objects that stretch over extensive, "potentially endless" periods of time (Esquenazi, 2014, p. 140). Instead of observing contemporary world building phenomena, however, a spatial perspective may be more appropriate for studying the attributes of serial television shows that form evolving, multi-faceted, open-ended and multi-stranded narratives.

2 Focusing on the temporality of serial narratives is useful for highlighting character and psychological changes (Martin, 2014; Jost, 2015), the repetition and variation of story elements (Esquenazi, 2014; Soulez, 2011), narrative complexity and "pyrotechnics" (Mittell, 2006, p. 35), narrative architecture and the propensity of narrative material to imitate life (Pescatore \& Innocenti, 2012), the relationship between narrative sequence and story closure (Dubois, 2015; Lifschutz, 2018), and the way in which serial shows constantly push back narrative closure to prolong their existence. The latest version of the Récit cinématographique by André Gaudreault and François Jost (2017) includes analyses of both films and serial television shows. It focuses on identifying the actions and time frames of serial shows and on unpicking storytelling in relation to constructed diegetic events.

3 Clearly, serial television shows have a time dimension and how long they last is also a measure of their commercial success. However, when considering the relationship between viewers and serialised storytelling, particularly in the digital age, which has lessened the hold of television programming schedules and led to a proliferation of media forms and narratives, time is not the only possible dimension (and approach). 
Through a perspective combining aesthetic analysis, narratology and the pragmatics of reception, we compare serial television shows to worlds that are artfully crafted in the pilot and gather detail through successive episodes, taking viewers into a new landscape which, once the show becomes successful, may prove to be either very complex or populated with engaging and reassuring characters, or both these things. In other words, we suggest analysing serial television shows as multi-directional, expanded and explorable spaces, as worlds or states of objects, situations, characters, laws of nature and other things.

While thematic approaches to the concept of space - monitored, travelled, protected or policed space, road movies, conquered territories, urban space, space and gender - are all possible, our contribution provides an analysis of fictional space in serialised shows as a starting point for multiple explorations. Our standpoint is to consider fictional space not just as a setting, but as being specific to the medium, as well as aesthetically and narratively key to the development of serial television shows, while qualifying the idea that their expansion depends only on the length of story- or timelines.

\section{The three layers of temporality - should we explore time?}

In 2014 in L'Art des séries télé, Jean-Pierre Esquenazi favoured a temporal approach. He wrote that "a serial show is the art of time" and explained that serialised stories are told over long periods, thus drawing on personal and collective memory (ibid., p. 140). ${ }^{1}$ Serial shows, like Swiss clocks, are inexhaustible "script machines" (ibid., p. 161). They are set to a specific formula to perform a triple function: defining a narrative, a style and a fictional universe. Three years later, Esquenazi conceded that the concept of a formula worked well for episodic shows, that is, with a new narrative in each episode, but was not as useful for studying intricate, interwoven narratives. He therefore refined his position by developing a partially spatial approach, based on tools for analysing expanded fictional worlds, with particular reference to Lubomír Doležel's theory. For Doležel, "it is obvious that work on the story is fundamental to the process of expanding a fictional universe. By constantly creating events and characters and exploring new time and space horizons in fictional worlds, story development adds complexity and fills gaps, while expanding and enriching the new worlds" (Esquenazi, 2017, p. 91). Though it considers time and space to be inherently linked, this tool remains tied to an essentially temporal vision of the serial television show, seeking to explain how it articulates "audiovisual editing" (in the sense of Deleuze and fundamentally connected to time) with "narrative editing", the analysis of which is helpful to capture the "time image" of a show (ibid., pp. 161-184).

6 In this respect, we note that serial temporality consists of at least three distinct, connected layers: diegetic time, narrative time and viewer time. The first, diegetic time, is time as experienced by the characters. This is the time over which a story is told, from a single day to several years. In some serial television shows, diegetic time is the narrative frame or the concept supporting the work of fiction. For example, in La Casa de Papel / Money Heist (Antena 3, 2017, Netflix, 2019-), several interwoven narratives take place over a twelve-day hostage standoff in Spain's national mint. Because most of the action takes place in a virtually unique closed space, narrative progression appears at first sight to be structured around time, which is displayed directly on the screen. 
Time marks out and constrains the narrative, while also conditioning post-production aesthetic choices, including the superimposed extra-diegetic time data. Conversely, in Narcos (Netflix, 2015-2017), the first two series tell the life story of the Medellín cartel up to the death of Pablo Escobar, over several decades. Diegetic time is elastic and often, aesthetically enhanced.

7 It is articulated with and contingent on narrative time, the number of hours over which the narrative unfolds. In Money Heist, this represents about 13 hours of viewing over 15 episodes. In some serial dramas such as 24 (Fox, 2001-2010, then 2014), diegetic time and narrative time coincide exactly in that instead of being a constraint, narrative time aids narration and is integral to it. 24 relates twenty-four hours in the lives of the characters over a twenty-four hour-long narrative divided into twenty-four episodes.

These two superimposed time frames happen over viewer time, which is real time as experienced by viewers, from discovering the first episode to figuring everything out in the last. Here, temporality is dependent on the programme's broadcasting schedule set by the television channel and/or on the production rate and interruptions. Broadcasting frequency can be daily or weekly and the broadcasting cycles annual or over several years. In its original format imagined by Fox, that is, when not watched back-to-back after its initial airing, 24 merges an hour in the life of the characters with an hour in the life of the viewers (a viewing hour consists here of pure televisual narration, thus including commercial breaks - as noted by John Ellis [2011], the same show watched in DVD format, without commercials, should be called 18). Narrative and viewing time frames, however, did not coincide exactly as series were not broadcast every 24 hours. Instead, the viewing time was scheduled to span twenty-four weeks in the life of viewers. In the case of the British drama Sherlock (BBC One, 2010-), there was a three-year gap between the second and the third series.

Admittedly, the three layers of temporality can also be found in film and literature: however, television's distinctiveness as a medium stems from having a stronger, more intimate and aesthetically critical relationship with the three time frames described, as it involves greater time elasticity, more ritualised television watching and greater viewer investment. While it allows an understanding of conventional television serials, the purely temporal perspective is limited for understanding television consumption patterns in the era of over-the-top media services and back-to-back viewing. Individual viewing practices and frequency make the observable features of serial television shows more complex, as emphasised by considerations on complex television (Mittell, 2015). The complexity and elasticity of time also show us that it is possible to investigate serial shows in terms of space in order to make sense of multiple superimposed layers.

\section{The spatial approach}

10 With the pragmatic recognition that serial shows have become detached from television schedules in the era of Netflix, Hulu and Amazon, reducing the usefulness of considerations on the coincidence of the three layers of temporality, recent studies on serial shows have proposed a spatial alternative to the temporal approach. By deploying strategies over several episodes, which connected viewers can navigate as they please since they are always at hand, storytelling creates space. At the same time, the viewers' activity, while happening over a given period of time - defined by the 
viewers themselves rather than by television schedules - amounts to an exploration of space. While our previous analysis focused primarily on a transmedia perspective (Boni \& Berton, 2019), this paper provides a spatial reading of serial shows, by paying attention to the aesthetic and narrative dimension and highlighting what we have termed exploratory storytelling. Our hypothesis is that space is a useful concept for grasping the extension/expansion mechanisms used by serial television shows. The aim is to characterise a form of immersion in passing from the time perspective, where viewers repeatedly return to a fictional contract they have entered into, to a spatial perspective, where they periodically delve into a habitable fictional world in which they can come and go as their level of immersion dictates.

11 Certain new serial shows follow a logic that is clearly more spatial than time based. How should we consider serial shows based on short series, closed narratives and resolved storylines such as anthologies? The spatial perspective opens up more opportunities for these. For example, in Fargo (FX, 2014-), the cast is renewed in each series, and the various strands in each connect to a greater meaning by retaining the same setting, the American Midwest. On the other hand, True Detective (HBO, 2014-) moves from one narrative space (Louisiana) in the first series to another (northern California) in the second, keeping the cornerstones of theme, tone, and aesthetic treatment. The anthology drama Black Mirror (Channel 4 2011-2014; Netflix 2016-) adopts this model, with narratives taking place in several locations, but using standalone episodes, in the same way as Alfred Hitchcock Presents in the 1950s (CBS 19551960; NBC 1960-1962), rather than a series structure. Serial television shows can potentially be limitless and keep on going for ever "according to an infinite narration mode" (Esquenazi, 2014, p. 140). Show series anchored in different fictional spaces share this connection to a distinct space as their common feature: space is both a narrative catalyst and an impulse for potential infinity for the collected stories. A spatial approach, still closely linked to the temporal approach, thus becomes useful.

According to this hypothesis, beyond following stories in the foreground of a fictitious setting, watching a serial television show also involves becoming familiar with a fictional space where material and mental worlds intersect, determining the serial narratives that develop and keep going within it. The approach of André Gardies is helpful in this regard. For Gardies, film narratives rely on the space in which they take place. In the film Le salaire de la peur (Clouzot, 1953), the geographical (North African), cultural (music and language), political (a country occupied by the French Army) and architectural (colonial city) setting is a considerable narrative vehicle, at times hindering narration, at others supporting it, but always an auxiliary to it (Gardies, 1993, pp. 107-136).

According to Gardies's spatial film theory (ibid., p. 102), the narrative is supported by a "system of relationships" between characters and space. This system in which space as location is the main "actant" is called "narrative space". In this perspective, "the hero's web of movements is determined less by a succession of empirical representations than by their need to go to specific locations to recover the values they need for their quest (ibid., p. 149). Gardies contends that every narrative essentially tells the story of a subject in relation to a space. This spatial perspective, when applied to serial shows with multiple - connected or unconnected - locations, is useful for describing their temporal (stories and characters) and spatial (propagation and exploration of locations) expansion. 
More so than for film, considering a serial chronotope naturally leads us to emphasise the need for a pragmatic approach in which the serial experience is viewed as a process. In this respect, world building theories provide an option for understanding serial processes as a major phenomenon of contemporary media culture (Wolf, 2013). The most widely recognised definition of the fictional world is that of Doležel. According to Doležel, a fictional world has three properties: it is imaginary - every unfolding narrative spins an image of the world it inhabits; coherent (in the Aristotelian sense) - a world property and its opposite cannot coexist; and accessible - it can be understood in reference to the knowledge we have of our own world through certain properties shared by both, such as human relationships (love, power, desire, fear) and physical laws ${ }^{2}$ (Doležel, 1985). Scholars, however, disagree about the consistency of these worlds. In this debate, contrary to other scholars of possible worlds for whom worlds are not built and exist only through the text (Umberto Eco, Doležel, Kendall Walton), Marie-Laure Ryan argues that fictional worlds are complete, meaning that they exist beyond the text and have the same consistency as our own. ${ }^{3}$ According to this point of view, serial exploration means clearing the fog around unknown parts of a pre-existing, complete fictional world, similar to the fog of war in a video game. ${ }^{4}$ This space, which has both a mental and a material existence, is called in Gardies's film studies (mentioned above), the "diegetic space", and in Ryan's (2012) literary theory "narrative universe", where narratives are spun and worlds are interwoven. Like a character in its own right, the space of a fictional world becomes more and more familiar with each episode as viewers delve into it. This dual abstract and material quality of film space and serial shows allows viewers to repeatedly immerse themselves in a fictional world, creating a sense of familiarity.

Ryan has contributed to the spatial approach in fiction studies by developing visual tools (through mapping) for understanding the chronotope in the light of the theory of possible worlds. This time-space inseparability is epitomised by her storyworld concept:

Storyworld is a concept that makes intuitive sense, but it is very difficult to define in a theoretically rigorous way. World suggests a space, but story is a sequence of events that develops in time. If we conceive of storyworlds as mental representations built during the reading (viewing, playing, among others) of a narrative text, they are not static containers for the objects mentioned in a story but rather dynamic models of evolving situations. We could say that they are simulations of the development of the story. The Russian critic Mikhail Bakhtin (1981) captured this inseparability of space and time in narrative through the concept of chronotope (Ryan, 2013, p. 364).

A storyworld is a dynamic, multi-directional space containing temporal elements (stories and characters) and belonging to a narrative universe, which may include several of them. For the anthologies studied here, each episode or series may be analysed as exploring new storyworlds in the wider narrative universe, in which different stories unfold and various characters come to life (Black Mirror, American Horror Story). The serial drama Fargo uses an even more complex model in that some elements, objects or characters belong to several storyworlds at once, blurring their boundaries. However, we could imagine, for the purposes of our analysis, that the film is one storyworld, and the serial show another. This would be useful since "as with Baktin's chronotope, whose function is to establish space-time relationships by making them visible, observable and thus analysable, storyworlds can render metaphorical fictional words 
visible and help organise them via patterns and maps. Space is a physical manifestation of time (Bakhtin, 1978, 391)" (Martinez, 2017, p. 56).

The serial space is progressively created by the actions that consumers perform in that space: they watch the title/credit sequence, which hints at what is to come in the space; they decide to immerse themselves in the world; they get to know it over several episodes through processes of densification and immersion; and they return to it whenever they want for successive viewings. We will now examine how these worlds are built, how they create stories and how they expand. While at this stage of our discussion, the concept of space seems appropriate for analysing serial televised shows, negotiating spatial "density" remains a challenge.

\section{Expanding and filling space over the run of a serial television show}

By adapting the literary concept of worlds to serial television shows, Esquenazi (2017, p. 161) established that the fictional universe forms the basis for serial narratives. This universe is often defined by a specific location, which he calls "centre of gravity". This may be the Cook County University Hospital in ER (NBC, 1994-2009); a mysterious island in Lost (ABC, 2004-2010) or Tony Soprano's family home (HBO, 1999-2007), the bar and café, respectively in How I Met Your Mother (CBS, 2005-2014) and Friends (NBC, 1994-2004), the police station in Hill Street Blues (NBC, 1981-1987), the motel in Bates Motel (A\&E, 2013-2017), the high school in Glee (Fox, 2009-2015), etc. These specific, recognisable spaces may be "the only setting of the serial show or its centre of gravity, to which is added a group of characters who may be attached to this location or who may simply pop up in it" (Esquenazi, 2017, p. 161). For example, using this definition, we can see that all the characters' actions in Game of Thrones (HBO, 2011-2019) - which exemplifies spatial serial shows with its changing title sequence representing a map and its plots centred on territorial disputes - converge to the King's Landing, the show's centre of gravity, where power is concentrated. The protection or conquest of this location initiates and fuels narration. ${ }^{5}$ Using Esquenazi's centre of gravity concept, we can see that serial spaces either develop from this centre outwards (centrifugal spaces) or grow inwards towards it (centripetal spaces).

Centrifugal spaces are places that are periodically visited from the centre of gravity. Many locations are visited over the episodes which allows an entire territory to be discovered. For example, in Fargo, many areas around the eponymous city in North Dakota are explored, and new cities appear in successive series of Games of Thrones as we are reminded by the map depicted in the title sequence, showing the locations explored in each episode.

Centripetal spaces are spaces where situations linked to the centre of gravity and its close surroundings are developed. This device is used in the sitcoms How I Met Your Mother (CBS, 2005-2014) and Friends (NBC, 1994-2004), in hospital shows ER and House (Fox, 2004-2012) and teen dramas such as Glee, in which several story levels take place in one (or two) central locations. In sitcoms, the aesthetic and narrative treatment of space depends on the mode of production and shooting, during which, as in theatre, an audience sits opposite the set. Three cameras between the bleachers and the set shoot a scene from three different positions, varying field size and scale, from full shots to 
close-ups. Camera movements are restricted to panning using a tripod and tracking shots, and zooming is limited by digital quality (since lenses can only be changed between scenes). The rules of this type of production usually dictate that one camera zooms in on a single character while another captures the reaction of a second or group of characters, and a third puts the narrative situation in context using a wider shot. The construction of a single space, with a reduced number of camera directions, ${ }^{6}$ the necessary use of closer shots, the limited number of angles and use of the same types of shots are all aesthetic consequences of the way in which these programmes are produced. Some of these spaces are so pervasive that they become as important as the characters who inhabit them in the viewers' imagination. This is true of Central Perk, a mythical café in the imaginary world of Friends, with its orange sofa floating in the centre like a raft.

Conversely, centrifugal spaces are usually produced in so-called film mode, outside studios, using more mobile cameras and many filming locations. The consequences of this production mode on filmed space are the use of multiple angles and shot scales, with the introduction of the establishing shot and wide shot. The narrative implication of this is an expansion of diegetic space, which as we have seen, has a catalytic effect on storytelling.

One characteristic of serial shows is that they build and expand space by creating multiple locations and stories; this space is thus "filled" at a later stage if the show becomes successful. For example, Twin Peaks (ABC, 1990-91, then Showtime, 2017) revolves around a police investigation, but does not progress in a linear fashion. Instead, the investigator, Dale Cooper circulates between several mysteries that the small village is hiding and through multiple facets of reality, which he grasps at the same time as the viewers. This format allows the killer to be identified well before the end of the second series, breaking with the conventions of television schedule storytelling and inviting viewers to follow a group of what were until then secondary characters who contribute to deepening the mysteries further. By suggesting that there is always more than what can be revealed in each episode, the show becomes exploratory. This exploration takes place as the serial drama unfolds.

\section{The opening sequence as a gateway and a means of periodic immersion into a fictional space}

In the chapter "Pouvoir des séries" (the Power of serial shows), Esquenazi (2017, p. 78) emphasises the immersive power of serial television: "because of its duration the serial television show has many excellent characteristics that facilitate televisual immersion. A serial television show is a fictional story broken down into several episodes broadcast over a long period." Viewers periodically return to the fictional contract they have entered into with the show. While the time aspect (repetition) is important, the immersive effect is also due to the building of a space. First, we can note the importance of opening sequences, through which the serial contract is negotiated, and which are useful for understanding how the show offers viewers a space to explore in a potentially infinite narration mode. Whether they are long (Games of Thrones, True Detective), short (Girls, HBO, 2012-2017), or made up of the first images in the episode (Fargo), opening sequences are like a gateway into a world and a fictional space. In television shows, opening sequences serve two purposes: to announce the beginning of 
a programme to viewers who may not be very attentive, and second, to introduce viewers to the universe and tone of a serial drama - and reacquaint them with these at each episode. Usually, opening sequences define the context, setting and characters and play the role of a gateway into the fiction. Opening sequences are one of the ways in which the show creates an environment, not just by exploring a world, but by building one (see an analysis by Boni \& Re, 2017; Boni, 2017). An essential trait of serial shows is to facilitate the densification of a universe, making them particularly conducive to viewer immersion.

For example, the title sequence of Twin Peaks does not introduce its characters as did the series with interwoven storylines or the soap operas of the time. Instead, viewers experience a slow immersion into a landscape without any human presence. The first image of the opening sequence shows a varied thrush, which then dissolves into an image of moving machinery in a small rural sawmill. In these shots, both spaces - the natural and the industrial - work on their own, as if they were governed by other forces, whether natural, supernatural or mechanical. These are followed by a long shot of the road to the fictional town of Twin Peaks, in which the fog and mountains seem tranquil, yet feel eerie. The mood imparted by the stillness and framing of this shot is then reinforced by the image of a tumbling waterfall shot from above, conveying at once beauty, strength and relentless motion in one direction. The length of the shots, slow and magical transitions, and sleepy imagery create a tranquil atmosphere, yet also imply something sinister and strange. The landscape seems both reassuringly familiar and hostile, influencing its inhabitants and their true nature.

The magical space of Twin Peaks creates a substratum for the narrative, influencing the actions, speech and appearance of the protagonists. It has a presence and is waiting to be filled with temporal elements such as characters and stories. Lasting two and a half minutes, the opening sequence introduces viewers to the show, establishing context and setting. Its true function is to suggest and entice (Re, 2016), creating a world of desirable things and themed or generic traits, for the benefit of viewers ready (or not) for the experience.

\section{The pilot and definition of space}

In some cases, there is no title sequence and the title and credits are superimposed on the images of the first episode. For Esquenazi, it is the whole first episode rather than the opening sequence that provides the tone of a serial drama, laying its foundations, delineating the serial narrative, fictional universe and style. This is the case with Fargo. The first episode of series one begins with a long, high-angle shot (making things appear much smaller) of a car struggling to appear on the skyline. Humans are very small indeed in this hostile landscape and the aesthetic barrier of the skyline probably feels insurmountable to them. In the following shots, the black and white of the initial images are tinged with red as the roadside is bathed in the light of the car's headlights. This red stain on the pure white snow and quiet, pitch-dark night hints at the inescapable bloody events to come. Some wild deer then cross the road, causing the vehicle to swerve off it and crash in the middle of a field in an explosion of snow.

These shots depict a frozen, hostile, inhospitable and dangerous land, which will turn out to be a force that the characters populating the show will need to contend with. This introductory scene ends with a shot/reverse shot between the driver who survives 
the crash and the deer that hit him. This confrontation suggests a struggle between humans and nature, as well as between humans and their own predatory nature. An analysis of the relationship between the characters and their (social, geographic and family) environment in the first two series reveals that the immoral characters are victims of the space they inhabit while the virtuous ones use it to further their investigation and restore justice (Martinez, 2017, pp. 64-67). In this opening scene without dialogue, all the genetic elements of the serial show are found in the landscape and lend themselves to an aesthetic analysis with implications for the narrative analysis.

\section{Is Fargo (FX, 2014-) a spatial serial drama?}

Noah Hawley, Fargo's showrunner and lead writer, described the show as a ten hourlong movie. However, this unconventional television show, as described by its creator, ${ }^{8}$ had a classic weekly airing on Fox. About his work on Fargo and Legion (FX, 2017-), Hawley explained: “We've got the time, right? It's not a two-hour movie. It's an 8-, or a 10- or a 12-hour movie. "Let's tell the parts of the story that you couldn't tell on the big screen." However, by "parts" Hawley meant stories as well as the locations and corners of the Coen brothers' Midwest he explored. In the eighth episode of the second series, a large leather-bound book opens and the camera draws us closer into a chapter taking place in Luverne, with a picture of Ed and Peggy, the central characters of this series (S1, E8 "The Castle"). We then understand that each series tells the story of a chapter in this book entitled The History of True Crime in the Midwest. But instead of following a chronological sequence - series one takes place in 2006, series two in 1978 and series three in 2010 - the narrated segments exhibit a spatial consistency, each one being identified by a Midwest location, such as "Luverne, Minnesota". When put together, such fragments of the narrative universe - the film is considered by Hawley to be one of these chapter fragments - introduce us to the American Midwest, partially shown in the film and in the fictional "true story". This exploration is more spatial than temporal.

The omnipresence of space through an emphasis on named locations (e.g. Fargo, Brainerd, Bemdiji, Luverne and Sioux Falls) as "perceivable fragment(s) of space(s)" (Gardies, 1993, p. 86) and symbolic places such as the police station, the roadside restaurant, the cabin in the forest, generates a special narrative energy. In all the chapters (including the film), the Midwest of the Coens generally opposes or helps the characters depending on whether they are law enforcers or gangsters, or city dwellers or country folk.

The analysis of space in serial shows through the concept of storyworlds, visited by viewers over successive episodes, highlights the ability of these worlds to accommodate characters and multi-directional narratives. Fargo is an example of a serial show in which the stories are created from spatial parameters associated with the American Midwest. Before the third series was aired, the channel chose a promotional paratext showing the space rather than the characters despite the star cast, or the stories, even though today's viewers can easily be led astray by more promising content. Short teaser videos put the space before the characters. The teasers showed a typically American geographic and socio-cultural environment: the backyard of a suburban house with an inflatable Santa Claus floating above it, the interior of a police station, a 
snow-covered road during a storm, a pharmacy front in the snow. There is also a bird as in the title sequence of Twin Peaks, perched on a snow-covered branch. An inhospitable geographic environment set against the backdrop of the American dream gives the show a flavour of "Siberia with family restaurants", as described by the Coen brothers when their film came out in 1996. It highlights the relationship individuals have with their environment, their local area, their values, their neighbours and the law, and the anonymity of a community wrapped up in thick parkas and sheltered by their cars. The harsh geographic and socio-cultural environment causes events to spiral out of control, leading to an irreversible horrific conclusion. Inside the fictional space, there are marks of the Coens' genre (thriller, comedy, detective film and film noir) and tone (irony and tragic comedy). Such promotional fragments create a landscape more than a setting, since as discussed by Philippe Leclerc (2011, p. 58) in his thesis on space in Terrence Malick films, "the 'physical' and 'material' landscapes of any film are landscapes in the sense that they play a role in the development and mental construction of an overall landscape, more complex and more abstract, a kind of general 'atmosphere' if you like" (Leclerc, 2011, p. 58). Hence the notion of sense of space, which is particularly meaningful in considering the transmedia dimension of Fargo: the spatial and narrative elements of the 1996 film can be found again, translocated into FX's recent narrative.

The concept of worlds proves to be an appropriate tool for investigating fictional spaces because it allows a partial analysis of expansion processes in serial shows. Worlds consist of what is shown as well as what is not, and what will be revealed.

\section{Worlds are reliant on the viewer's imagination}

Processes of world building and densification do not depend solely on what is shown of these worlds. The world remains imaginary and viewers largely participate in reconstituting continuity in a discrete, incomplete space. Even in film and serial television, space is not necessarily what is shown (this is what makes it different to location and setting [Gardies, 1993]). The French show Calls (Canal+, 2017), for example, is set in the age of the image as an aural experience with a strong spatial potential achieved by plunging viewers into an apocalyptic world. It is unusual in that it does not show any landscape in this world, relying on the concept of found footage for sound. The characters are represented in space by flickering lights, whose presence on the image and intensity vary according to the protagonists' location and how loud they are speaking. Their names and conversations appear as subtitles in relation to these visual cues, occupying the image while mapping the characters' movements and interactions. This audio serial show is different from a podcast since it is also visual and relies on the viewer's imagination and knowledge of the real world - the convention that places New York on the left of the Atlantic Ocean and Paris on the right of a map, for example - to build the world it projects. Rather than just being seen and heard, the world is visualised and creates a greater sense of space than the figurative examples we are used to. Paradoxically, this audio show reveals the process by which a serial fictional world is created and expanded and the narrative mechanics of spatialisation at work, by replacing a viewed space by a perceived space. 


\section{Serial worlds} dramas can also be analysed in terms of spatial exploration. Twin Peaks. The Return (Showtime, 2017) is an example of this: while the show provides a typically David Lynch experience, the core narrative of Dale Cooper's investigation is not refined much further (or at any rate, this is not the main focus). In contrast, space is a powerful presence: the world of Twin Peaks, its locations, several of the characters who inhabited it 27 years ago, now older, can be recognised. Returning to Twin Peaks is like having the opportunity to inhabit and re-explore afresh this complex world. Another example is provided by Fargo, which extends the film's universe without offering either a remake (the characters and stories are different) or a reboot (timelines overlap without replacing each other). The concept of space exploration is a good alternative to rewriting.

\section{Conclusion}

By focusing on the phenomenon of serial television, we have emphasised the pragmatic dimension of the storytelling experience. Considering the limits of a time-based approach based on conventional television programming schedules with their intervals and seasons, which is no longer as appropriate as it used to be in the age of streaming, and using the theory of fictional worlds, we have highlighted the relevance of a spatial approach. This is especially valuable for making sense of anthologies and the multiple reboots and remakes in the large media franchises to which serial shows belong. As seen in the few examples discussed, space often supports storytelling. Moving away from its status as a mere setting, space has become an explorable world, which viewers find out about depending on series parameters as well as according to their own practices and cognitive dispositions. Considering serial shows as world building experiences is thus a useful way of understanding the success mechanisms of serial works and analysing the significance and implications of their longevity, a trait which is in itself an analytical challenge. 


\section{BIBLIOGRAPHY}

Bakhtin, M. (1978) [1975]. Esthétique et théorie du roman. Translated from Russian by D. Olivier. Paris: Gallimard.

BONI, M. (2017). Psycho/Bates Motel : hyperdiégèse et réactivation sélective. Intermédialités 28-29. Online: https://www.erudit.org/fr/revues/im/2016-n28-29-im03201/1041077ar/.

BONI, M. \& BERTON, M. (forthcoming). Comment étudier la complexité des séries télévisées ? : problèmes et méthodes, TV/Series.

BONI, M. \& RE, v. (2017). Here Be Dragons. La mappa come soglia, racconto, creazione. In: BONI, M. \& $\mathrm{RE}, \mathrm{V}$. (eds.), Game of Thrones. Una mappa per immaginare mondi. Milano/Udine: Mimesis, pp. 105128.

DOLEŽEL, L. (1985). Pour une typologie des mondes fictionnels. In: Parret, H. \& Ruprecht, H.-G. (eds.), Exigences et perspectives de la sémiotique. Recueil d'hommages pour A. J. Greimas. Amsterdam: John Benjamins, pp. 7-23.

DUBOIS, F.-R. (2015). Organisation proleptique et clôture narrative dans les séries télévisées. Écrans 4, pp. 110-120.

Eco, U. (1985) [1979]. Lector in fabula. Le rôle du lecteur, or, La Coopération interprétative dans les textes narratifs. Translated from the Italian by M. Bouzaher. Paris: Librairie générale française.

ELLIS, J. (2011). Interstitials: How the "Bits in Between" Define the Programmes. In: Grainge P (ed.), Ephemeral Media: Transitory Screen Culture from Television to YouTube. Basingstoke: Palgrave Macmillan, pp. 59-69.

ESQUENAZI, J.-P. (2014) [2010]. Les Séries télévisées. L'avenir du cinéma ? Paris: Armand Colin.

ESQUENAZI, J.-P. (2017). Éléments pour l'analyse des séries. Paris: L'Harmattan.

GARDIES, A. (1993). L'Espace au cinéma. Paris: Méridiens Klincksieck.

GAUDREAULT, A. \& JOST, F. (2017). Le Récit cinématographique. Films et séries télévisées. Paris: Nathan.

JOST, F. (2015). Les Nouveaux Méchants. Quand les séries américaines font bouger les lignes du bien et du mal. Montrouge: Bayard.

LECLERC, P. (2011). Le Traitement de l'espace dans Badlands et Days of Heaven, de Terrence Malick. Masters thesis: Université de Montréal.

LIFSCHUTZ, V. (2018). This is the End. Tours: Presses universitaires François-Rabelais.

MARTIN, B. (2014) [2013]. Des hommes tourmentés. Le nouvel âge d'or des séries. Translated from the English by L. Cohen. Paris: Éditions La Martinière.

MARTINEZ, C. (2017). De Fargo à Fargo (Coen 1996; FX 2014-) : la notion d'espace dans un phénomène médiatique complexe, l'adaptation d'un film en série télévisée. Masters thesis: Université de Montréal.

MITTELL, J. (2006). Narrative Complexity in Contemporary American Television. Velvet Light Trap 58. pp. 29-40. 
MITTELL, J. (2015). Complex TV: The Poetics of Contemporary Television Storytelling. New York: New York University Press.

PESCATORE, G. \& INNOCENTI, V. (2012). Information Architecture in Contemporary Television Series. Translated from the Italian by S. and M. Francoli. Journal of Information Architecture 4 (1-2), pp. 5772.

RE, V. (2016). From Saul Bass to Participatory Culture: Opening Title Sequences in Contemporary Television Series. Necsus. Online: https://necsus-ejms.org/saul-bass-participatory-cultureopening-title-sequences-contemporary-tv-series/.

RYAN, M.-L. (2012). Space. In: Hühn, P. et al. (eds.), Handbook of Narratology. Berlin/New York: De Gruyter, online: http://www.lhn.uni-hamburg.de/article/space.

RYAN, M.-L. (2013). Transmedial Storytelling and Transfictionality. Poetics Today 34 (3), pp. 361388.

SAINT-GELAIS, R. (2011). Fictions transfuges. La transfictionnalité et ses enjeux. Paris: Éditions Le Seuil.

SOULEZ, G. (2011). La double répétition : structure et matrice des séries télévisées. Mise au point 3. Online: https://journals.openedition.org/map/979.

WOLF, M. J.P. (2013). Building Imaginary Worlds: The Theory and History of Subcreation. New York: Routledge.

\section{NOTES}

1. Concerning the role of collective memory and knowledge communities ("collective intelligence") in creating complexity, see also Jason Mittell (2006, p. 31).

2. Some of the laws of our world may be transgressed in these fictional worlds. In this case, their specific qualities need to be explained as recognised rules as soon as they are introduced, otherwise these worlds risk becoming inconsistent. This is why we consider magic to be acceptable in fictional worlds (Ryan).

3. The issue of completeness and incompleteness of textual worlds sets Doležel, Eco and Walton apart from Thomas Pavel, Ryan and John Woods. A brief history of this debate can be found in Fictions transfuges (Saint-Gelais, 2011, pp. 49-70).

4. Fog of war is a term used by players to describe hidden areas on a map in games such as Civilization, Warcraft, Starcraft, etc. The space is unveiled as the characters go through it.

5. With Castle Black (the principal place of resistance) and the Wall (where the longterm threat comes from), this is one of only three locations to remain in the original title sequence, which changes with each territory explored.

6. In the studio of Friends, an apartment wall in one of the sets concealed an opening hidden under a picture, through which a camera could film, providing another angle.

7. The idea of filling the holes in a world has been attributed to Eco (1985, p. 158).

8. In an interview with Vanity Fair in 2016 he said, "Let's not rely on all the old formulas. Let's not have a case of the week" (http://vanityfair.com). 


\section{ABSTRACTS}

This contribution suggests a spatial perspective for studying serial television shows. Using an approach based on the pragmatics of reception, with which we consider serial television shows to be processes and experiences for exploring diegetic multi-directional spaces, this article combines aesthetic and narratological analysis and compares serial television shows to fictional worlds. Through various examples of shows from the 1990s to more recent ones, this essay considers serial dramas as world building experiences and seeks to understand the mechanisms through which they retain their immersive power over the long term. Working with spatial theories of film and media studies, we conceive space as a world or a diegetic landscape, thus supplementing existing methods for the analysis of serial television shows that consider time to be the main narrative catalyst.

Partant d'une approche pragmatique de la réception qui considère la série télévisée comme processus et expérience exploratoire d'un espace diégétique pluridirectionnel, cet article allie analyse esthétique et narratologique en comparant les séries télévisées à des mondes fictionnels. À travers divers exemples de programmes des années 1990 à aujourd'hui, l'objectif est de penser les séries comme des expériences de construction de mondes et de comprendre les mécanismes de leur pouvoir immersif sur le long terme. L'espace, conçu en tant que monde ou territoire diégétique, permettra de compléter les méthodes d'analyse des séries télévisées présentant le temps comme moteur narratif principal et s'appuiera sur les théories spatiales des études cinématographiques et médiatiques.

\section{INDEX}

Keywords: serial TV shows, space, fictional worlds, narrative exploration, immersion, narrative expansion, longevity, title sequence, pilot

Mots-clés: série télévisée, espace, mondes fictionnels, exploration narrative, immersion, expansion narrative, longévité, générique, épisode pilote

\section{AUTHORS}

\section{MARTA BON}

Université de Montréal, CA-H3C 3J7 Montréal (Québec), Canada

\section{CAMILLE MARTINEZ}

Université de Montréal, CA-H3C 3J7 Montréal (Québec), Canada 